\title{
Relational Operator
}

National Cancer Institute

\section{Source}

National Cancer Institute. Relational Operator. NCI Thesaurus. Code C48354.

A boolean operator used to specify a greater-than, less-than, or equal-to relationship. 